\title{
A TRIAL OF ANTIGEN MARIANUM AS AN ADJUNCT OF D.D.S. IN THE TREATMENT OF LEPROMATOUS LEPROSY
}

\author{
D. W. BeCKeTt, M.A., M.D., D.T.M. AND H. \\ Medical Superintendent Fiji Leprosy Hospital, Makogai.
}

Antigen marianum was originally prepared in Lyons at the Leprosy Research Laboratory of the Propagation of the Faith by the late Sister Mary Suzanne, S.M.S.M. According to Blanc, it is a culture of acido-alcohol resistant bacilli from a human leproma which is later killed to prepare the antigen. As there is no certainty that the organism in culture is indeed Mycobacterium leprae, Sister Mary Suzanne proposed for it the name of Mycobacterium marianum in honour of the Blessed Virgin to whom her Religious Congregation is dedicated. The antigen prepared from this strain, originally known as Chauvire antigen, has also become known as Antigen marianum.

The antigen was first used experimentally by Blanc, Prost Lemaire, Kuna and Nkoa in the Cameroons in 1952 and their first report was published in 1953 . In this they report that $73.3 \%$ of lepromin-negative lepromatous patients and $61 \%$ of similar indeterminate cases became lepromin positive after a six to twelve months' course of the antigen.

From these results, Blanc and his colleagues decided to experiment with the antigen as a form of treatment based on an immunological line of attack rather than a chemotherapeutic one. They reported their results in 1955 . In their series of 457 patients, there were ten deaths which were not attributable to the antigen. Of the remainder, $21.7 \%$ showed no improvement, $79.9 \%$ improved ana $56.4 \%$ showed considerable improvement.

We in Makogai were most interested in these reports as the Fiji Leprosy Hospital is staffed by the Missionary Sisters of the Society of Mary and Sister Mary Suzanne was, in fact, one of the first two Sisters to arrive here on the foundation of the hospital in 1911. She worked in Makogai from 1911 until 1932 when she departed after a short stay in Rotuma, to France. It was in Makogai, we like to think, that she learned the facts about leprosy and developed that interest in the disease that led her into research in the subject. My predecessor, Dr. W. H. McDonald, therefore wrote to her in 1954 and obtained from her sufficient Antigen marianum to treat 84 patients. Sister Mary Suzanne displayed throughout the course of the trial a great interest in it and its progress, and the news of her sudden death in November 1957, just as the results were being correlated, was a sad blow to all at Makogai, both staff and patients. 


\section{The Trial}

The present trial of Antigen marianum was commenced towards the end of 1954 by my predecessor in this post, Dr. W. H. McDonald, M.B.E. His object at the time was to see if the postulated immunological effect of the antigen could be made use of synergistically to enhance the value of DDS in treatment of lepromatous leprosy. Eighty-four cases were picked because they were examples of that class which is such a problem to workers in leprosy. All were lepromatous cases whose disease appeared inactive or only very slightly active but whose skin smears remained persistently positive. Out of these 84 cases, 61 were picked by random selection for treatment with the antigen and DDS, while the remaining 23 cases were given DDS alone so as to act as controls.

Most unfortunately, when the time came to start the second six-month course (see 'method' below), Dr. McDonald was on leave and the Medical Officer who was relieving him mistakenly started all 84 patients on to the antigen. It thus results that cases numbers 62 to 84 received only two courses of treatment.

When the time came to correlate results, therefore, there were no accurate controls. In order to obtain some idea of the value of the antigen, all those cases of lepromatous leprosy who were not very active at the start of the experiment but who had not been given the antigen were picked as retrospective controls. These numbered 21 and were generally rather more active than the 84 patients who had been included in the trial.

\section{Method}

Every patient had a lepromin test performed and was then given $0.1 \mathrm{ml}$. of Antigen marianum by intradermal injection at monthly intervals for six months. The injections were given into the skin of the palmar aspect of the forearm and the two arms were used alternately. A month after the last injection, the lepromin test was repeated. Three of these six-monthly courses were given with six months interval between each.

\section{Reaction}

After each injection, every patient ran a temperature. In the majority of cases, this was not high (below $100^{\circ} \mathrm{F}$. or $37.7^{\circ} \mathrm{C}$.) and lasted for only one day. However, about one-fifth of the patients ran a high temperature for two or three days and this was particularly noticeable after the earlier injections.

At the site of the injection, a raised, red and angry-looking nodule was formed in every case. As the trial proceeded, these became more severe and broke down to form very chronic and unsightly ulcers. Several patients who bear no other deformity from 
their leprosy will carry the scars of these ulcers as most unwelcome stigmata for the rest of their days.

It appeared then that the general reaction to the antigen was greater in the earlier doses but the local protective reaction was greater as the trial advanced and the patients' resistance built up.

\section{Lepromin Reaction}

Before the trial, out of the 84 cases, $13(15.5 \%)$ were lepromin positive and $71(84.5 \%)$ were lepromin negative. After three courses of antigen, $69(82.1 \%)$ were positive and only $15(17.9 \%)$ were negative.

Of the 61 patients who underwent the first six months period, 52 were lepromin negative. After one six month's course, 30 of these were positive, 21 were still negative and one had been discharged. This represents a conversion rate of $57.7 \%$ after six injections of the antigen and compares unfavourably with Blanc's figure of $73.3 \%$ but is better than Relvich's one of $30 \%$.

Crude lepromin was used throughout the trial. It was prepared in the laboratory of the Medical Department in Suva by Dr. Gosden for whose help in this connection we are greatly indebted. The material used was taken from patients in Makogai.

\section{Progress of Patients}

Skin smears were examined every three months but for convenience only those taken af ter each six-monthly course are recorded. A simple classification of bacteriological activity is used in Makogai and the records of each smear are recorded as follows:

- $\quad=$ No mycobacterium leprae found.

$+\quad=$ Up to 10 single bacilli in the whole slide.

$++\quad=$ Single bacilli in over 10 fields or more than 10 bacilli in the whole slide.

$+++\quad=$ Small globi present and/or the bacilli being clumped.

$+-++=$ The fields look red.

It is my experience that a more precise classification than this is both cumbersome and unnecessary. Improvement can be seen at a glance on this scale. Admittedly, a change from, say, 8 bacilli to 3 bacilli cannot be shown but this seems to me to be well within the limits of normal human error.

Clinical improvement was calculated by three-monthly physical examination though, again, only those remarks recorded after each course of antigen are shown.

The examination was entirely objective and included inspection of the whole body for skin lesions, palpation of all peripheral sensory and mixed nerves for thickening and tenderness and examination 
for deformities or sensory or trophic changes. The patients were not asked whether they felt better and the findings recorded are entirely the examiner's opinion and no: that of the examined.

After the trial was over, an assessment of the clinical and bacteriological state of the patients was made. Out of the 84 patients, $31 \%$ had been discharged, $43 \%$ were judged to have been improved and $26 \%$ were stationary or worse. The corresponding figures for the 21 controls were $19 \%$ discharged, $57 \%$ improved and $24 \%$ no better. If the discharged and improvements are combined, then $74 \%$ of those given the antigen were better in condition by the end of the trial. But the respective figure for the controls is $76 \%$.

As the controls were rather worse than the test cases before the trial started, one would expect fewer of them to be discharged in the ordinary course of events and $19 \%$ of them to be discharged in proportion to $31 \%$ of the test cases seems, in my opinion, to be statistically unimportant.

Details of bacteriological and clinical progress of all 84 cases and 21 controls were recorded and are available.

\section{Discussion}

It is a matter open to some doubt as to whether it is possible to treat leprosy by the induction of an antibody response to a vaccine or an allergic response to an antigen.

As Muir (1948) says: "M. leprae meets with such tolerance in its host that it can multiply to astronomic numbers without producing recognisable symptoms. It would be surprising, therefore, if injection of a comparatively small additional number of such organisms could immunise a patient in whom the disease has already been firmly established," and the position does not appear to have changed during the ten years that have elapsed since these words were written.

Relvich, however, states that, in his opinion, on theoretical grounds, the idea behind the use of antigen for the treatment of lepromatous leprosy appears to be sound. Blanc merely assumes it to be self-evident that immunological treatment is not only effective but is to be preferred to chemotherapy.

The results we have obtained with Antigen marianum appear to me to leave no doubt that some immunological response has been obtained. The question then arises as to whether this response has done the patients any good and the only honest answer that can be given is in the negative.

Does merely converting a negative lepromin reaction into a positive one convert a case of lepromatous leprosy into a tuberculoid one? Muir says, "The difference between the tuberculoid and the lepromatous case is not just one of immunity. Nor can it be correct to say it is one of allergy alone. It appears rather that there 
is a n unknown factor. . . "' I contend that that factor is still unknown. I do not believe that we have converted lepromatous leprosy to tuberculoid and I do not know for how long these converted lepromin reactions are going to stay positive.

Even if it were possible to produce this change, it seems extremely doubtful as to whether it would be beneficial to the patient. In the pre-sulphone era it would, perhaps, have been justifiable to attempt artificially to convert lepromatous to tuberculoid. Nowadays, however, it is the experience of almost all leprologists that the lepromatous type of the disease responds more easily, more quickly and more completely to treatment. I think, therefore, that such antigens are probably not only not beneficial but may even be harmful.

The acid test is, of course, whether such immunised patients have, in fact, benefited from treatment and I think that this trial shows that they have not. It is too early to say whether the antigen has had any adverse effect on them and it is proposed to follow up this report with a further comparison after a year of their progress with that of the controls. Many of them carry unsightly scars as a result of the antigen which they would not otherwise have had.

\section{SUMmaRY}

1. A three-year trial of Antigen marianum in the treatment of lepromatous leprosy was carried out on 84 patients. There were 21 controls who were picked retrospectively as the designated group of controls were given the antigen in error. All 105 patients were also on routine DDS.

2. Three six-monthly courses of one injection of antigen a month were given to 61 cases and two such courses to the other 23. There was a six-months' rest period between each course.

3. Before the trial $13 \%$ of the cases were lepromin positive. After the trial, the figure was $82.1 \%$, and $57.7 \%$ of negative cases became positive after the first six months.

4. After the trial $31 \%$ of patients had been discharged, $43 \%$ were improved and $26 \%$ were stationary or worse. Corresponding figures for the controls were $19 \%, 57 \%$ and $24 \%$. It is concluded that antigen marianum was of no value when given as an adjunct to DDS in the treatment of lepromatous leprosy.

\section{ACKNOWLEDGMENTS}

My thanks are due to the patients who took part so enthusiastically in the trial and also to the Sisters of the Staff of the Fiji Leprosy Hospital who were at all times of the utmost assistance. In particular, I should like to record my gratitude to Sister Mary Prisca, S.M.S.M., who conducted the trial and kept the records and to Sister Mary Kieran, S.M.S.M., and Sister Mary Alberta, S.M.S.M., who did all the tedious laboratory work so devotedly and so accurately. 
I should also like to record our gratitude to the late Sister Mary Suzanne, S.M.S.M., who supplied us with generous quantities of the antigen and wrote us several long letters of advice as to procedure.

My thanks are also due to Dr. P. W. Dill-Russell, C.B.E., Director of Medical Services, Fiji, and Inspector-General, South Pacific Health Service, for permission to publish.

\section{REFERENCES}

Blanc, M., Prost et al. (1953). Int. J. Leprosy, p. 595.

Blanc, Prost, et al. (1955). Annales de Biologie de Lille.

Muir, E. (1948) Manual of Leprosy. Chapter 17.

Relvich, A. L. (1957). Leprosy Review 28, 4 Oct. 1957, p. 150. 